\title{
"Overshoot" of $\mathrm{O}_{2}$ Is Required to Maintain Baseline Tissue Oxygenation at Locations Distal to Blood Vessels
}

\author{
Anna Devor,,${ }^{1,2,3}$ Sava Sakadžić, ${ }^{1}$ Payam A. Saisan, ${ }^{2}$ Mohammad A. Yaseen, ${ }^{1}$ Emmanuel Roussakis, ${ }^{4}$ Vivek J. Srinivasan, ${ }^{1}$ \\ Sergei A. Vinogradov, ${ }^{4}$ Bruce R. Rosen, ${ }^{1}$ Richard B. Buxton, ${ }^{3}$ Anders M. Dale, ${ }^{2,3}$ and David A. Boas ${ }^{1}$ \\ ${ }^{1}$ Martinos Center for Biomedical Imaging, Massachusetts General Hospital, Harvard Medical School, Charlestown, Massachusetts 02114, Departments of \\ ${ }^{2}$ Neurosciences and ${ }^{3}$ Radiology, University of California San Diego, La Jolla, California 92093, and ${ }^{4}$ Department of Biochemistry and Biophysics, University \\ of Pennsylvania, Philadelphia, Pennsylvania 19104
}

In vivo imaging of cerebral tissue oxygenation is important in defining healthy physiology and pathological departures associated with cerebral disease. We used a recently developed two-photon microscopy method, based on a novel phosphorescent nanoprobe, to image tissue oxygenation in the rat primary sensory cortex in response to sensory stimulation. Our measurements showed that a stimulusevoked increase in tissue $\mathrm{pO}_{2}$ depended on the baseline $\mathrm{pO}_{2}$ level. In particular, during sustained stimulation, the steady-state $\mathrm{pO}_{2}$ at low-baseline locations remained at the baseline, despite large $\mathrm{pO}_{2}$ increases elsewhere. In contrast to the steady state, where $\mathrm{pO}_{2}$ never decreased below the baseline, transient decreases occurred during the "initial dip" and "poststimulus undershoot." These results suggest that the increase in blood oxygenation during the hemodynamic response, which has been perceived as a paradox, may serve to prevent a sustained oxygenation drop at tissue locations that are remote from the vascular feeding sources.

\section{Introduction}

Brain activity relies largely on mitochondrial oxidative metabolism to meet the associated energy demands (Chance et al., 1962). The oxygenation level of cerebral tissue is therefore one of the most basic physiological parameters. As such, it can be used as a biomarker in animal models of neurodegenerative disease, either to detect a departure from normal physiology or as an objective criterion in determining the effectiveness of treatment. However, our ability to probe the microscopic availability of oxygen during different levels of neuronal activity has been limited to point measurements using oxygen electrodes (Fatt, 1976). Such measurements have provided an invaluable insight into tissue oxygen dynamics in cerebral (Thompson et al., 2003; Viswanathan and Freeman, 2007) and cerebellar cortex (Offenhauser et al., 2005), but they have also demonstrated a substantial degree of variability, which has been attributed to possible differences in electrode position relative to the vascular oxygen sources (Erecińska and Silver, 2001; Masamoto et al., 2003). Oxygen electrodes have also been used to map intravascular oxygenation on the cortical surface (Vovenko, 1999; Sharan et al., 2008; Vazquez et al., 2010). These and other studies (Vanzetta and Grinvald, 1999; Ances et al., 2001; Yaseen et al., 2009) have established the basic properties

\footnotetext{
Received April 19, 2011; revised July 5, 2011; accepted Aug. 3, 2011.

Author contributions: A.D., B.R.R., R.B.B., A.M.D., and D.A.B. designed research; A.D., S.S., and M.A.Y. performed research;P.A.S., M.A.Y., E.R., V.J.S., and S.A.V. contributed unpublished reagents/analytic tools; A.D., S.S., and P.A.S. analyzed data; A.D., B.R.R., R.B.B., A.M.D., and D.A.B. wrote the paper.

We gratefully acknowledge support from NINDS (Grants NS051188 and NS057198 to A.D., NS057476 and NS055104 to D.A.B.) and NIBIB (Grants EB00790 to A.M.D., EB009118 to A.D., EB2066 to B.R.R., and EB007279 to S.A.V.).

This article is freely available online through the J Neurosci Open Choice option.

Correspondence should be addressed to Anna Devor, Departments of Neurosciences and Radiology, University of California San Diego, La Jolla, CA 92093. E-mail: adevor@ucsd.edu.

DOI:10.1523/JNEUROSCI.1968-11.2011

Copyright $\odot 2011$ the authors $\quad 0270-6474 / 11 / 3113676-06 \$ 15.00 / 0$
}

of intravascular and extravascular oxygen changes during increases in neuronal activity and associated functional hyperemia (vasodilation and an increase in cerebral blood flow and volume); however, the microscopic landscape of oxygen changes in cerebral cortex remains largely uncharted. In particular, because of technological challenges, little is known about the oxygenation state and stimulus-evoked oxygenation changes of tissue remote from the feeding vascular sources (midway between capillaries).

We recently developed a new technology for in vivo measurements of $\mathrm{pO}_{2}$ in the cerebral cortex (Sakadžić et al., 2010) based on two-photon phosphorescence lifetime microscopy (2PLM) (Finikova et al., 2008; Lebedev et al., 2008). 2PLM enables the measurement of interstitial (tissue) $\mathrm{pO}_{2}$ with unprecedented spatial resolution and is well suited to imaging of $\mathrm{pO}_{2}$ changes during stimulus-evoked activation. In the present study, we applied our new technology in the rat primary somatosensory cortex (SI) as it was responding to sensory stimulation. In particular, we investigated the dependence of stimulus-evoked $\mathrm{pO}_{2}$ changes on the baseline $\mathrm{pO}_{2}$ level of oxygenation and stimulus duration. Our findings indicate that, during sustained stimulation, the muchdiscussed overshoot in oxygenation (for review, see Raichle and Mintun, 2006; Paulson et al., 2010) was not observed at those tissue locations with the lowest baseline $\mathrm{pO}_{2}$. These results are consistent with the idea that an overall steady-state increase in oxygenation is required to prevent hypoxia during persistent increases in neuronal activity and thus to ensure survival of the tissue farthest from vessels.

\section{Materials and Methods}

Animal preparation. We used 21 female Sprague Dawley rats (110-200 g). All experimental procedures were approved by the Massachusetts General Hospital Subcommittee on Research Animal Care. All animal procedures and mapping of the center of the neuronal response were 
A

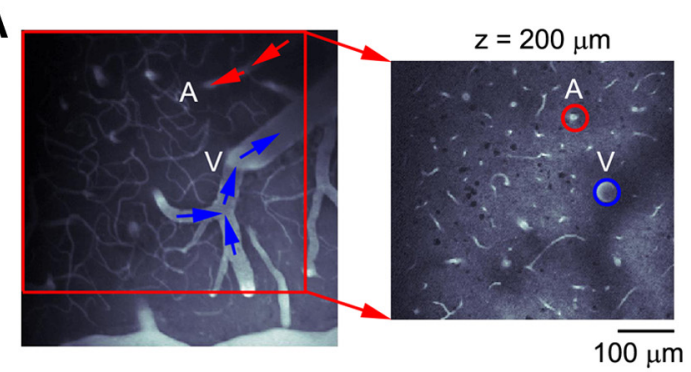

B

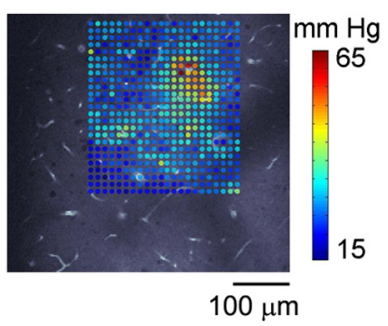

C
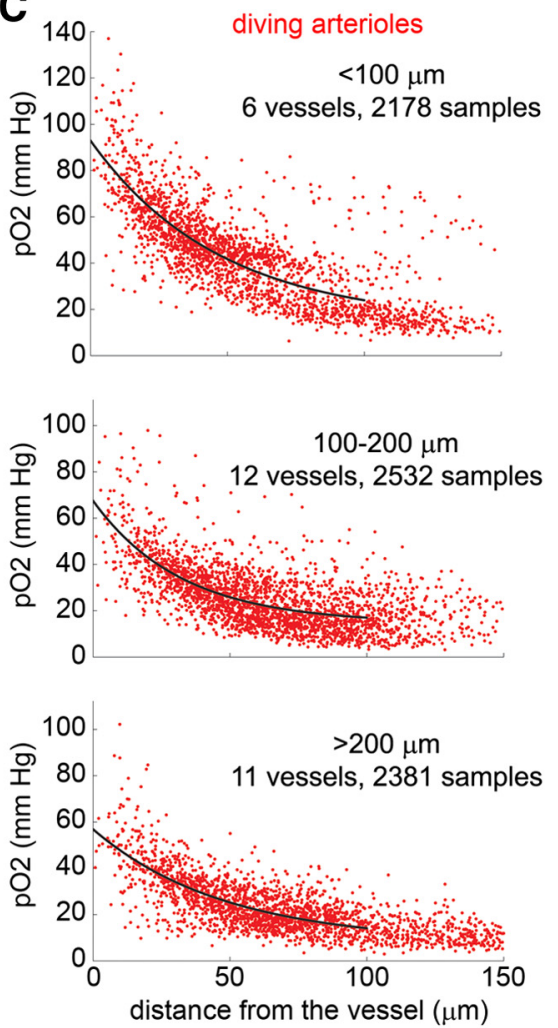
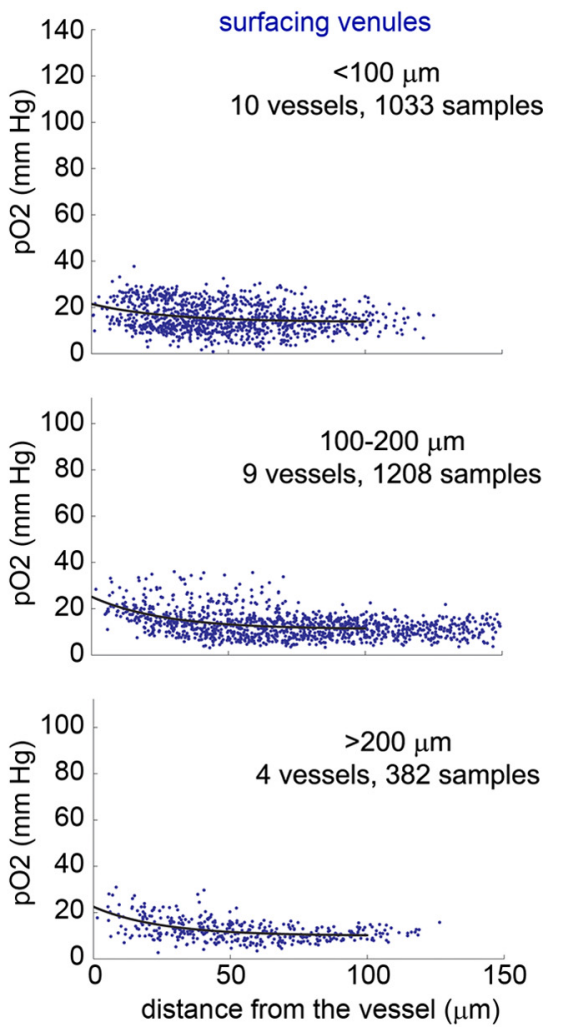

Figure 1. Baseline $\mathrm{pO}_{2}$ relative to diving arterioles and surfacing venules. $A$, An image of the surface vasculature calculated as a maximum intensity projection of an image stack $0-300 \mu \mathrm{m}$ in depth obtained using a $4 \times$ objective. Individual images were acquired every $10 \mu \mathrm{m}$. The fluorescent contrast is due to intravascular FITC. The image on the right shows a zoomed-in view of the region within the red square on the left at the depth plane of $\mathrm{p}_{2}$ measurements, $200 \mu \mathrm{m}$ below the surface. $A$, Diving arteriole; $V$, surfacing venule. $\boldsymbol{B}, A$ grid of measured $\mathrm{p}_{2}$ values superimposed on the vascular reference image. $\boldsymbol{C}_{,} \mathrm{pO}_{2}$ as a function of the radial distance from the center of a blood vessel: diving arterioles (left) or surfacing venules (right). The $\mathrm{p}_{2}$ values were obtained from grid measurements, as with the example in $\boldsymbol{A}$ and $\boldsymbol{B}$. Data from multiple vessels from multiple animals are overlaid on each plot.

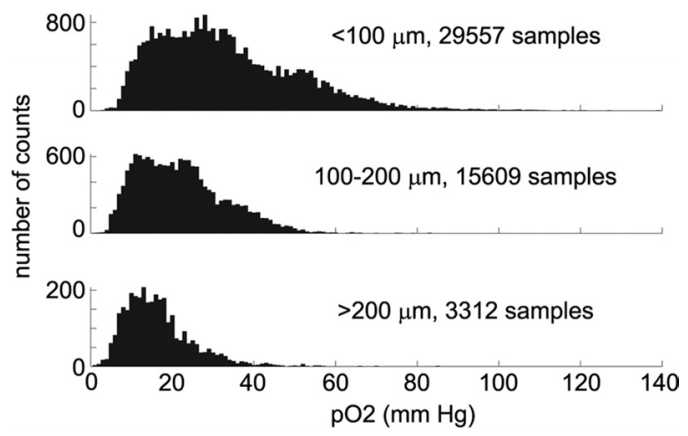

Figure 2. Distribution of the measured $\mathrm{p}_{2}$ values as a function of cortical depth. Categories and numbers of samples are indicated above the histograms.

performed as described by Devor et al. (2007, 2008). Briefly, rats were anesthetized with isoflurane during surgical procedures and $\alpha$-chloralose during data acquisition. During the surgical procedures, cannulas were inserted into the femoral artery and vein for measurement of blood pressure/blood gas and drug infusion.

The $\sim 2.5 \times 2.5 \mathrm{~mm}$ cranial window remained open for $\sim 10 \mathrm{~min}$. During this time, the center of the neuronal response was mapped using surface potential recordings (Devor et al., 2007), and the PtP-C343 probe was microinjected at the center of neuronal activation using a pneumatic PicoPump (WPI, PV830). After the injection, the cranial window was covered with a glass coverslip. The space between the exposed brain surface and the glass was filled with $1 \%(\mathrm{w} / \mathrm{v})$ agarose (Sigma) in artificial CSF (ACSF) and sealed around the coverslip with dental acrylic. After a single injection, data were collected for up to $4 \mathrm{~h}$ without having to increase the laser power. To visualize the vasculature, $\sim 0.3 \mathrm{ml}$ of $5 \%(\mathrm{w} / \mathrm{v})$ solution of $2 \mathrm{MDa}$ fluorescein-conjugated dextran (FITC, FD-2000S, Sigma) in physiological saline was injected intravenously (Tian et al., 2010).

PtP-C343 probe. PtP-C343 synthesis and calibration were performed as described by Finikova et al. (2008) and the supplementary material of Sakadžić et al. (2010). PtP-C343 is a dendritic oxygen probe in which phosphorescence of metalloporphyrins upon two-photon excitation is enhanced by intramolecular Förster-type energy transfer from two-photon coumarin-343 antenna chromophores located in the same probe molecule. Oxygen sensitivity of the probes is regulated by dendritic encapsulation of the core metalloporphyrin, whereas peripheral polyethyleneglycol residue groups on the dendrimer isolate the probes from contact with biological macromolecules in the environment. The calibration plot for conversion of lifetime to $\mathrm{pO}_{2}$ was obtained in independent oxygen titration experiments where $\mathrm{pO}_{2}$ was detected by a Clark-type oxygen electrode as described by Rozhkov et al. (2002).

Sensory stimulus and synchronization with data acquisition. The stimulus, delivered by a dedicated PC, consisted of a train of electrical pulses $(3 \mathrm{~Hz}, 100 \mu \mathrm{s})$ delivered to the forepaw through a pair of thin needles implanted under the skin. We used stimulus durations of either 2 or $20 \mathrm{~s}$ with interstimulus intervals of 30 and $100 \mathrm{~s}$, respectively. The intensity was adjusted to provide stimulation around the twitch threshold $(\sim 1 \mathrm{~mA})$. Stimulation onset was triggered at a preset delay after optical data acquisition began. Twenty and eight stimulus trials were presented at each imaging location for the 2 and $20 \mathrm{~s}$ stimuli, respectively.

Two-photon microscopy. Two-photon imaging was performed using a custom-built microscope setup as described by Sakadžić et al. (2010). A low-magnification objective (Olympus XLFluor4x/340, numerical aperture $=0.28$ ) was used to obtain FITC images of the surface vasculature across the entire cranial window to aid navigation around the cortical vasculature. FITC fluorescent output was detected by a dedicated photomultiplier tube.

Data analysis. All image processing was performed using customdesigned software in MATLAB (MathWorks). Analysis of phosphorescent decays was performed as described by Sakadžić et al. (2010). After 
A
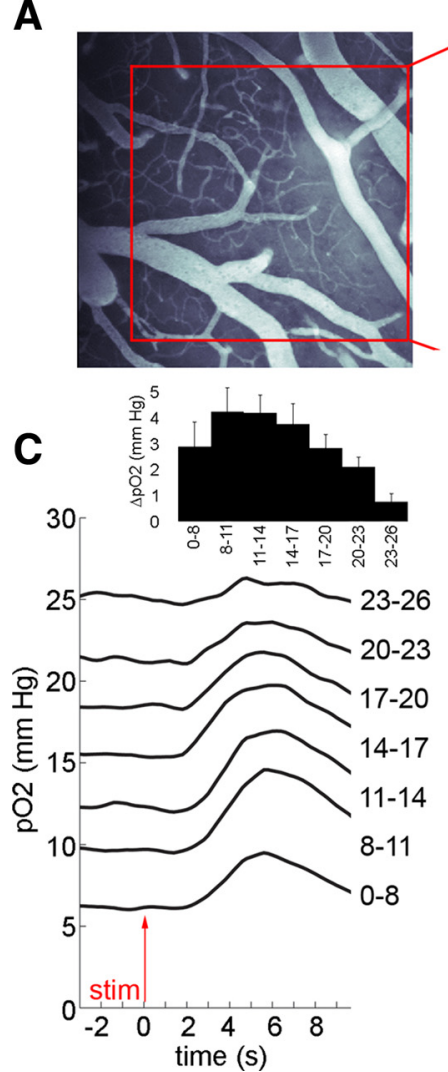

$300 \mu \mathrm{m}$

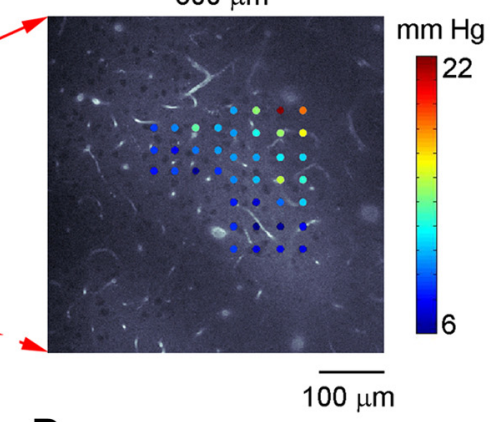

D

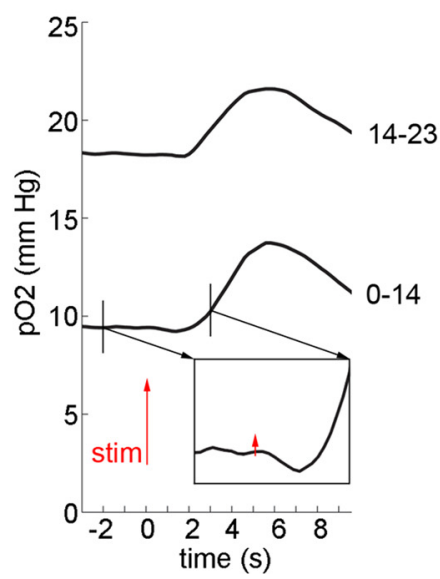

B

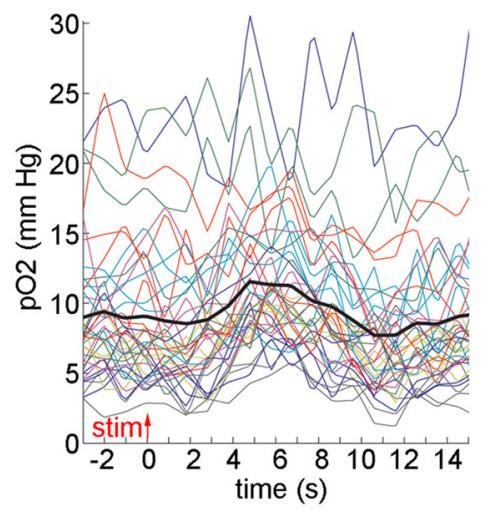

E

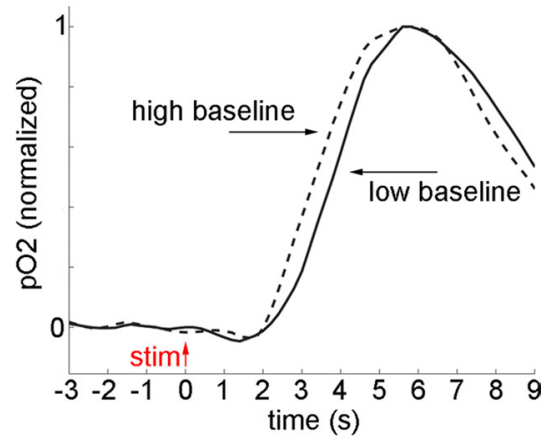

Figure 3. Tissue $\mathrm{p}_{2}$ changes in response to transient stimulation. $\boldsymbol{A}, \boldsymbol{B}$, An example set of measurements from a plane $300 \mu \mathrm{m}$ below the cortical surface. $\boldsymbol{A}$, Points used to measure stimulus-evoked responses, color-coded according to the prestimulus (baseline) $\mathrm{pO}_{2}$, are superimposed on the vascular reference image. A corresponding FITC image of the surface vasculature is shown on the left. $\boldsymbol{B}$, Time courses of $\mathrm{p}_{2}$ change extracted from each point shown in $A$. The thick black curve shows the average. The red arrow in this and other figures indicates stimulus onset. $C$, Averaged time courses, grouped according to the baseline $\mathrm{pO}_{2}$. The groups are indicated on the right. The inset shows mean peak $\mathrm{pO}_{2}$ increase from the baseline $\left(\Delta \mathrm{p} \mathrm{O}_{2}\right)$ for each baseline category. The error bars represent $\mathrm{SE}$ across subjects. $\boldsymbol{D}$, The same data as in $\boldsymbol{C}$. The averaged time courses are grouped according to the baseline, above and below $14 \mathrm{mmHg}$. $\boldsymbol{E}$, The same time courses as in D, baseline-subtracted and normalized to the peak amplitude.

specifying the measurement points, a randomization algorithm was applied to the temporal order in which the points were sampled. For grid measurements (Figs. 1-3), 2000 excitation cycles were averaged at each sampling point before moving the galvanometer mirrors to the next point. For dynamic measurements (Figs. 3, 4), 50 excitation cycles per stimulus trial were averaged per time point at each measurement location. Phosphorescent decays were fit with a single-exponential function using the trial-averaged data. One thousand and 400 excitation cycles were averaged per time point for the 2 and $20 \mathrm{~s}$ stimuli, respectively. The number of locations for the dynamic measurements was adjusted to allow us to revisit the location within $\sim 1 \mathrm{~s}$ ( $1 \mathrm{~Hz}$ sampling rate). The locations of the $\mathrm{pO}_{2}$ measurements were coregistered with FITC. Colorcoded measured $\mathrm{pO}_{2}$ values are overlaid on vascular images (grayscale) in Figures 1 and 3. Individual vascular territories were manually segmented from the coregistered images.

Statistical analysis was performed using The R Project for Statistical Computing (http://www.r-project.org) using a linear mixed-effect model implemented in the lme 4 package, where trends observed within a subject [e.g., the dependence of peak $\mathrm{pO}_{2}$ increase on the initial (prestimulus) $\mathrm{pO}_{2}$ ] were treated as fixed effects, while the variability between subjects was considered as a random effect. Observations within an animal subject were considered dependent; observations between subjects were considered independent. The measurements were group-averaged within each subject based on the prestimulus $\mathrm{pO}_{2}$ using the bins (categories), as indicated in Figures 3 and 4 . For each measurement point, the baseline was estimated as the average of values within a $4 \mathrm{~s}$ window before stimulus onset. The plateau amplitude in response to the $20 \mathrm{~s}$ stimulus was estimated as the average of values within a 15-20 s window following the stimulus onset.

\section{Results}

Diving arterioles supply $\mathrm{O}_{2}$ to the surrounding tissue

To investigate the spatial distribution of interstitial ("tissue") $\mathrm{pO}_{2}$ during the baseline (resting) level of neuronal activity, we imaged grids of $\sim 600$ points covering $\sim 200 \times 200 \mu \mathrm{m}$ in-plane at a given cortical depth. Figure $1, A$ and $B$, shows an example of a grid collected from a plane crossing a diving arteriole and a surfacing venule (Fig. $1 \mathrm{~A}$, labeled $\mathrm{A}$ and $\mathrm{V}$ ). For each plane, a corresponding "reference" vascular image of intravascular FITC fluorescence was acquired immediately after the $\mathrm{pO}_{2}$ measurements were taken for coregistration of the measurement points in the coordinate system of the vascular network. The grid of measurement points in Figure $1 \mathrm{~B}$, color-coded according to the $\mathrm{pO}_{2}$ level (in $\mathrm{mmHg}$ ), is superimposed on the reference vascular image. Ninety-eight individual grids were collected from 92 planes in 21 subjects, ranging in cortical depth from 20 to $350 \mu \mathrm{m}$. To examine the dependence of the baseline $\mathrm{pO}_{2}$ values on their location within the vascular network, we traced diving arterioles and surfacing venules from the cortical surface to the $\mathrm{pO}_{2}$ measurement plane. At the measurement plane, we segmented the arterioles and venules, based on the coregistered vascular reference images (see Materials and Methods), and we measured the behavior of the baseline $\mathrm{pO}_{2}$ within individual vascular territories as a function of radial distance from the corresponding arteriole or venule crossing the imaging plane. There was a gradient of $\mathrm{pO}_{2}$ around diving arterioles (Fig. 1C, left). In addition, smaller gra- 
A
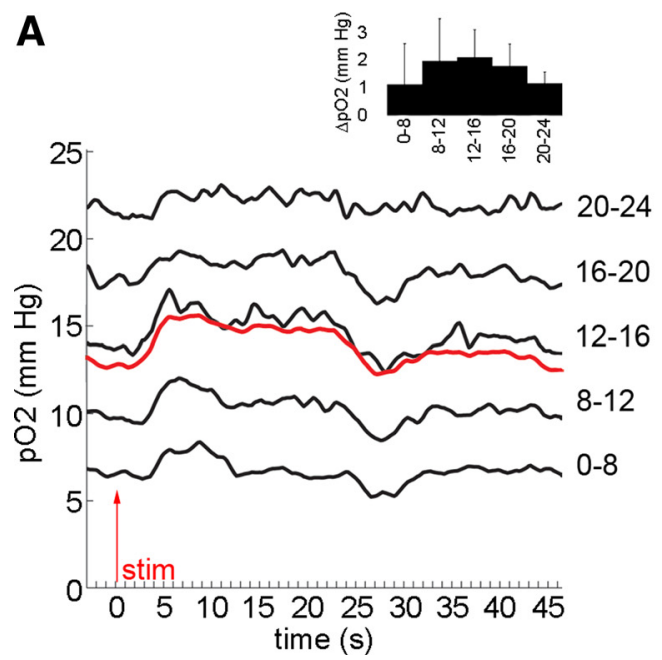

B

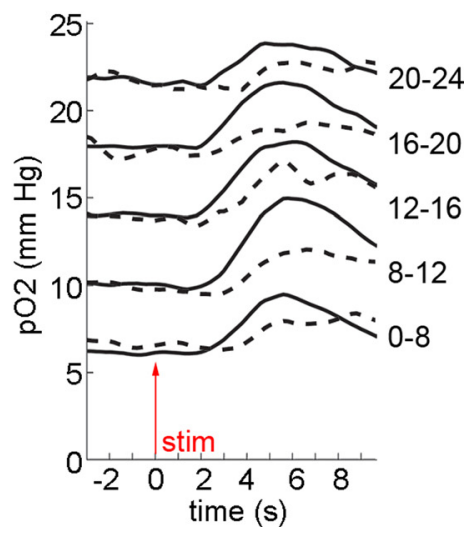

Figure 4. Tissue $\mathrm{pO}_{2}$ changes in response to sustained stimulation. $\boldsymbol{A}$, Averaged $\mathrm{pO}_{2}$ time courses in response to the $20 \mathrm{~s}$ stimulus. The data were grouped according to the baseline $\mathrm{pO}_{2}$. The groups are indicated on the right. The red line shows the average. The inset shows mean $\mathrm{p}_{2}$ increase from the baseline $\left(\Delta \mathrm{pO}_{2}\right)$ during the plateau response for each baseline category. The error bars represent $S E$ across subjects. $\boldsymbol{B}, A$ zoomed-in view of the first $10 \mathrm{~s}$ during the sustained stimulus (dashed line). The response to 2 s stimulus, group-averaged using the same baseline bins, is overlaid in solid black.

dients were observed around the majority of surfacing venules (Fig. $1 C$, right). We divided the measured grids into three depth categories: $<100 \mu \mathrm{m}, 100-200 \mu \mathrm{m}$, and $>200 \mu \mathrm{m}(200-350$ $\mu \mathrm{m})$. For each depth category in Figure $1 C$, the distribution of $\mathrm{pO}_{2}$ measurements as a function of the radial distance is shown for arterioles (red) and venules (blue), up to $150 \mu \mathrm{m}$ from the vessel. The number of measurements for each category is noted above the plots. The overall distribution of the measured $\mathrm{pO}_{2}$ values at different depths across subjects $(n=21$ subjects) is shown in Figure 2. In each case, the decay of $\mathrm{pO}_{2}$ with distance was fitted with an exponential function plus offset (black curves). For each plot, the intercept with the $y$-axis can be used to estimate the average intravascular $\mathrm{pO}_{2}$ for that depth category and vessel type. Arteriolar $\mathrm{pO}_{2}$ (Fig. 1C, left) decreased with depth from $\sim 90 \mathrm{mmHg}$ at $<100 \mu \mathrm{m}$ to $\sim 55 \mathrm{mmHg}$ at $>200 \mu \mathrm{m}$. The most superficial value is in general agreement with previous studies of surface vasculature using oxygen electrodes (Vovenko, 1999; Vazquez et al., 2010).

Transient increase in $\mathrm{pO}_{2}$ in response to stimulation varies as a function of baseline $\mathrm{pO}_{2}$

To image $\mathrm{pO}_{2}$ changes in response to a brief ( $2 \mathrm{~s}$ duration) stimulus, we decreased the number of measurement points to $\sim 50$ to achieve our target temporal resolution of $\sim 1 \mathrm{~Hz}$ while maintaining a sufficient signal-to-noise ratio. Figure $3, A$ and $B$, shows an example of stimulus-evoked $\mathrm{pO}_{2}$ imaging at a single plane 300 $\mu \mathrm{m}$ below the surface. Measurement points, color-coded according to the baseline (prestimulus) $\mathrm{pO}_{2}$ values, are superimposed on the corresponding vascular reference image in Figure $3 \mathrm{~A}$ (right). Figure $3 \mathrm{~B}$ shows $\mathrm{pO}_{2}$ time courses extracted from each of the measurement points in $A$. Whereas time courses from individual points are "noisy," the average across all points (the thick black curve) shows a clear increase in $\mathrm{pO}_{2}$ after stimulation. In particular, visible stimulus-induced increases were observed at relatively low baseline levels (Fig. $3 B, \sim 10 \mathrm{mmHg}$ ), well below the arteriolar $y$-intercepts in Figure $1 C$. Thus, the $\mathrm{pO}_{2}$ response might vary as a function of the baseline $\mathrm{pO}_{2}$ in the parenchymal range, in tissue fed by the capillary bed.
To test this hypothesis, we groupaveraged measured time courses, across locations and experimental subjects $(n=$ 17 subjects), according to their baseline $\mathrm{pO}_{2}$, which was estimated from the prestimulus time. We focused on tissue that was located away from major arterioles. This was achieved by implementing a baseline threshold: only points with baseline $\mathrm{pO}_{2}$ values $<26 \mathrm{mmHg}$ were considered. The resulting group-averaged time courses are shown in Figure 3C. For baseline values $>10 \mathrm{mmHg}$, the magnitude of the $\mathrm{pO}_{2}$ increase in response to stimulation gradually decreased with increasing baseline $(p=0.001$, linear mixed-effects model implemented in $R$, see Materials and Methods). Below $10 \mathrm{mmHg}$, the $\mathrm{pO}_{2}$ response had a tendency to decrease with decreasing baseline (Fig. 3C, compare the two bottom curves); however, this trend was not statistically significant across subjects.

In tissue remote from capillary sources, increases in $\mathrm{pO}_{2}$ will likely be delayed because of a combination of vascular transit time and diffusion of oxygen in tissue. One would expect to observe at these remote locations the largest temporal mismatch between the (fast) onset of oxygen consumption increase and the (slow) increase in oxygen delivery, resulting in a negative $\mathrm{pO}_{2}$ change. Indeed, locations within the lowest baseline category, which would be found between capillaries, exhibited a small initial negative signal [the "initial dip" (Malonek and Grinvald, 1996)] (Fig. $3 D)$. The $\mathrm{pO}_{2}$ signal at points with low baseline $(<14 \mathrm{mmHg}$, Fig. $3 E$, solid line) had a tendency to rise more slowly than points with a higher baseline $(14-23 \mathrm{mmHg}$, Fig. $3 E$, dashed line). These trends did not reach statistical significance across subjects, most likely because of the limited signal-to-noise ratio of the measurements.

\section{Steady-state increase in $\mathrm{pO}_{2}$ in response to stimulation varies} as a function of baseline $\mathrm{pO}_{2}$

In a subset of subjects $(n=7)$, we used a long ( $20 \mathrm{~s}$ duration) stimulus in addition to the $2 \mathrm{~s}$ stimulus to produce a sustained increase in tissue oxygen consumption in a subset of locations away from major feeding/draining vessels. The long stimulus produced a transient increase followed by a plateau response and a poststimulus "undershoot" below the baseline (Fig. 4A). A similar signal time course, including the plateau and undershoot phase, is routinely observed with fMRI and optical methods in hemodynamic responses to long-duration stimuli (Buxton et al., 2004). At the lowest baseline (Fig. $4 \mathrm{~A}$, the bottom curve), an increase in $\mathrm{pO}_{2}$ was observed during the transient but not the steady-state $\mathrm{pO}_{2}$ regime. In contrast, at higher baselines (Fig. $4 \mathrm{~A}$, 8-12 and $12-16 \mathrm{mmHg}$ ), an increase in $\mathrm{pO}_{2}$ was observed throughout the response. In fact, in the baseline range below 16 $\mathrm{mmHg}$, the amplitude of the steady-state response continuously increased with increasing baseline ( $p=0.05, n=4$ subjects, linear mixed-effects model, see Materials and Methods). At even higher baselines (Fig. 4A, 16-20 and 20-24 mmHg), the steadystate amplitude gradually decreased ( $p=0.04, n=5$ subjects, linear mixed-effects model, see Materials and Methods). The red curve in Figure $4 A$ shows a mean over the entire range $(0-24$ 
$\mathrm{mmHg}$ ), similar to what one might observe with a measurement method lacking fine spatial resolution.

A comparison of the transient response to the two stimulus conditions (Fig. $4 \mathrm{~B}$ ) suggested that the $\mathrm{pO}_{2}$ increase in response to the long stimulus was delayed and reached lower amplitudes than did the $\mathrm{pO}_{2}$ increase in response to the $2 \mathrm{~s}$ stimulus. This observation is consistent with sustained oxygen consumption throughout (and beyond) the transient phase in response to the long stimulus, counteracting the effect of increased oxygen delivery. For the $2 \mathrm{~s}$ stimulus, on the other hand, the stimulus and the associated increase in oxygen consumption are roughly over by the onset time of the flow-induced $\mathrm{pO}_{2}$ increase.

\section{Discussion}

We used a technology we recently developed for $\mathrm{pO}_{2}$ imaging (Sakadžić et al., 2010) to measure cerebral tissue oxygenation during manipulation of neuronal activity in vivo. This technological advance allowed us to image landscapes of tissue $\mathrm{pO}_{2}$ with two-photon spatial resolution down to $350 \mu \mathrm{m}$ below the cortical surface. These data, the first of their kind, provide unbiased highresolution sampling of tissue oxygenation as a function of depth and distance from blood vessels (Figs. 1,2). The decrease in arteriolar $y$-intercepts with increasing cortical depth and the $\mathrm{pO}_{2}$ gradients observed in the tissue around diving arterioles indicate that oxygen leaks into the tissue through the walls of diving arterioles. This conclusion is in agreement with prior indirect observation based on imaging of NADH, which showed a close spatial association between patterns of NADH fluorescence and arteriolar geometry (Kasischke et al., 2011), as well as with intravascular $\mathrm{pO}_{2}$ measurements (Sakadžić et al., 2010). We also observed a small increase in tissue oxygenation around the majority of venules, in particular, those close to the cortical surface. This might have been the result of an increase in near-surface intravenous $\mathrm{pO}_{2}$ as was observed in our previous intravascular $\mathrm{pO}_{2}$ measurements (Sakadžić et al., 2010, their Fig. 2C) and by photoacoustic microscopy (Hu et al., 2009).

A common concern when performing deep two-photon imaging is the possibility of signal contamination resulting from probe excitation in the volume above the focal plane (Theer and Denk, 2006). However, clear $\mathrm{pO}_{2}$ gradients in tissue around diving arterioles were also detected close to the cortical surface where the optical conditions were optimal. Moreover, because $\mathrm{pO}_{2}$ in the superficial cortical tissue is, on average, higher than that in deep tissue, contamination from near-surface signals would bias the measurements toward higher rather than lower values-in the opposite direction from what was observed experimentally. Finally, we could resolve the cellular structure in our phosphorescent survey images throughout the imaged depth (data not shown). This would not be possible if excitation of the probe outside the focal volume contributed significantly to the detected signal.

The arteriolar and venous $y$-intercepts estimate the high and low boundaries, respectively, for intravascular capillary $\mathrm{pO}_{2}$ for the same depth range. Capillary $\mathrm{pO}_{2}$ is expected to vary between these limits, decreasing with distance from a respective precapillary arteriole. Although we did not attempt in the present study to classify measurements based on their distance from capillary network elements, the baseline variation in $\mathrm{pO}_{2}$ shown in Figure 3 likely reflects the distance from capillary oxygen sources. The maximal response amplitude around $10-15 \mathrm{mmHg}$ is likely to occur close to those capillaries that exhibit a large increase in intravascular $\mathrm{pO}_{2}$ during the hemodynamic response. On the other hand, as is the case with arterioles, highly oxygenated cap- illaries (close to precapillary arterioles) are not expected to show large changes in intravascular oxygenation during the hemodynamic response. Therefore, tissue in proximity to these vascular elements would exhibit a smaller stimulus-evoked increase in $\mathrm{pO}_{2}$. Indeed, we noted that the $\mathrm{pO}_{2}$ response decreased toward the higher baselines. This suggests that, although diving arterioles served as major sources in sculpting the resting oxygen landscape, the stimulus-evoked increase in tissue oxygenation was driven by an increase of oxygen supply in the downstream capillary bed.

The onset of the $\mathrm{pO}_{2}$ increases in tissue is expected to be delayed relative to the onset of dilation response and intravascular $\mathrm{pO}_{2}$ increase because of several factors: (1) the time needed for diffusion of oxygen into the tissue, (2) vascular transit time, and (3) the counteracting effect of the increase in oxygen consumption (cerebral metabolic rate of oxygen, $\mathrm{CMRO}_{2}$ ) during increased neuronal activity. The effect of $\mathrm{CMRO}_{2}$ in delaying the onset of tissue $\mathrm{pO}_{2}$ increase should scale with the stimulus duration (Fig. $4 \mathrm{~B}$ ). Thus, the slow onset of tissue $\mathrm{pO}_{2}$ increase $(>2 \mathrm{~s}$, Figs. 3,4$)$ contradicts neither our previous observation of vasodilation onset in the 300-500 ms range (Tian et al., 2010), nor a recent report of a $350 \mathrm{~ms}$ fMRI signal onset in response to a single-shock electrical stimulus (Hirano et al., 2011). Moreover, the current data are in agreement with previous oxygen electrode recordings, which consistently demonstrated longer-lasting initial dips and slow onsets of tissue $\mathrm{pO}_{2}$ increases (Thompson et al., 2003; Viswanathan and Freeman, 2007) relative to what has been observed with optical imaging of hemoglobin oxygenation (Malonek and Grinvald, 1996). Finally, a recent report on tissue $\mathrm{pO}_{2}$ imaging in the olfactory bulb using a 4-s-long odor stimulus demonstrated that the $\mathrm{pO}_{2}$ increase lagged by $\sim 3 \mathrm{~s}$, preceded by the initial dip (Lecoq et al., 2011).

After the initial observations by Fox and Raichle (1986), the increase in blood oxygenation in response to an increase in neuronal activity and the associated increase in $\mathrm{CMRO}_{2}$ (the "overshoot" in blood flow response), which is routinely observed using macroscopic imaging methods, has been perceived as a paradox or uncoupling (Raichle and Mintun, 2006; Paulson et al., 2010). In contrast to macroscopic fMRI and PET signals, the twophoton imaging technology in the present study allowed simultaneous imaging of $\mathrm{pO}_{2}$ at many spatially resolved microscopic locations with various $\mathrm{pO}_{2}$ baselines. Our results indicate that the apparently paradoxical increase in vascular oxygenation might be needed to maintain the baseline oxygenation level at tissue locations with low baseline $\mathrm{pO}_{2}$. These locations are remote from the vascular feeding sources and most vulnerable to hypoxia (Fig. 4). Furthermore, the presence of transient decreases during the initial dip and poststimulus undershoot suggests that the hemodynamic response is specifically required and evolutionarily calibrated to prevent sustained tissue hypoxia during prolonged periods of elevated neuronal activity. On the other hand, the overshoot and undershoot of $\mathrm{pO}_{2}$ in the transient regime may reflect the underlying vascular machinery, which is optimized to reach quickly the correct steadystate level of oxygen delivery.

Further development of the imaging technology, for example combining the $\mathrm{pO}_{2}$ imaging method described here with optical coherence tomography for imaging of blood flow (Srinivasan et al., 2010), will enable measurement of tissue oxygen consumption, leading to unprecedented opportunities for investigation of cerebral metabolism and validation of existing methods for calculation of oxygen consumption based on noninvasive imaging signals (Buxton, 2010). 


\section{References}

Ances BM, Wilson DF, Greenberg JH, Detre JA (2001) Dynamic changes in cerebral blood flow, $\mathrm{O} 2$ tension, and calculated cerebral metabolic rate of $\mathrm{O} 2$ during functional activation using oxygen phosphorescence quenching. J Cereb Blood Flow Metab 21:511-516.

Buxton RB (2010) Interpreting oxygenation-based neuroimaging signals: the importance and the challenge of understanding brain oxygen metabolism. Front Neuroenergetics 2:8.

Buxton RB, Uludag K, Dubowitz DJ, Liu TT (2004) Modeling the hemodynamic response to brain activation. Neuroimage 23 [Suppl 1]:S220-S233.

Chance B, Cohen P, Jobsis F, Schoener B (1962) Intracellular oxidationreduction states in vivo. Science 137:499-508.

Devor A, Tian P, Nishimura N, Teng IC, Hillman EM, Narayanan SN, Ulbert I, Boas DA, Kleinfeld D, Dale AM (2007) Suppressed neuronal activity and concurrent arteriolar vasoconstriction may explain negative blood oxygenation level-dependent signal. J Neurosci 27:4452-4459.

Devor A, Hillman EM, Tian P, Waeber C, Teng IC, Ruvinskaya L, Shalinsky MH, Zhu H, Haslinger RH, Narayanan SN, Ulbert I, Dunn AK, Lo EH, Rosen BR, Dale AM, Kleinfeld D, Boas DA (2008) Stimulus-induced changes in blood flow and 2-deoxyglucose uptake dissociate in ipsilateral somatosensory cortex. J Neurosci 28:14347-14357.

Erecińska M, Silver IA (2001) Tissue oxygen tension and brain sensitivity to hypoxia. Respir Physiol 128:263-276.

Fatt I (1976) Polarographic oxygen sensors. Cleveland: CRC.

Finikova OS, Lebedev AY, Aprelev A, Troxler T, Gao F, Garnacho C, Muro S, Hochstrasser RM, Vinogradov SA (2008) Oxygen microscopy by twophoton-excited phosphorescence. Chemphyschem 9:1673-1679.

Fox PT, Raichle ME (1986) Focal physiological uncoupling of cerebral blood flow and oxidative metabolism during somatosensory stimulation in human subjects. Proc Natl Acad Sci U S A 83:1140-1144.

Hirano Y, Stefanovic B, Silva AC (2011) Spatiotemporal evolution of the functional magnetic resonance imaging response to ultrashort stimuli. J Neurosci 31:1440-1447.

Hu S, Maslov K, Tsytsarev V, Wang LV (2009) Functional transcranial brain imaging by optical-resolution photoacoustic microscopy. J Biomed Opt 14:040503.

Kasischke KA, Lambert EM, Panepento B, Sun A, Gelbard HA, Burgess RW, Foster TH, Nedergaard M (2011) Two-photon NADH imaging exposes boundaries of oxygen diffusion in cortical vascular supply regions. J Cereb Blood Flow Metab 31:68-81.

Lebedev AY, Troxler T, Vinogradov SA (2008) Design of metalloporphyrinbased dendritic nanoprobes for two-photon microscopy of oxygen. J Porphyr Phthalocyanines 12:1261-1269.

Lecoq J, Parpaleix A, Roussakis E, Ducros M, Houssen YG, Vinogradov SA, Charpak S (2011) Simultaneous two-photon imaging of oxygen and blood flow in deep cerebral vessels. Nat Med 17:893-898.

Malonek D, Grinvald A (1996) Interactions between electrical activity and cortical microcirculation revealed by imaging spectroscopy: implications for functional brain mapping. Science 272:551-554.

Masamoto K, Takizawa N, Kobayashi H, Oka K, Tanishita K (2003) Dual responses of tissue partial pressure of oxygen after functional stimulation in rat somatosensory cortex. Brain Res 979:104-113.

Offenhauser N, Thomsen K, Caesar K, Lauritzen M (2005) Activity-induced tissue oxygenation changes in rat cerebellar cortex: interplay of postsynaptic activation and blood flow. J Physiol 565:279-294.

Paulson OB, Hasselbalch SG, Rostrup E, Knudsen GM, Pelligrino D (2010) Cerebral blood flow response to functional activation. J Cereb Blood Flow Metab 30:2-14.

Raichle ME, Mintun MA (2006) Brain work and brain imaging. Annu Rev Neurosci 29:449-476.

Rozhkov V, Wilson DF, Vinogradov SA (2002) Phosphorescent Pd porphyrin-dendrimers: tuning core accessibility by varying the hydrophobicity of the dendritic matrix. Macromolecules 35:1991-1993.

Sakadžić S, Roussakis E, Yaseen MA, Mandeville ET, Srinivasan VJ, Arai K, Ruvinskaya S, Devor A, Lo EH, Vinogradov SA, Boas DA (2010) Twophoton high-resolution $3 \mathrm{D}$ imaging of partial pressure of oxygen in cerebral vasculature and tissue. Nat Methods 7:755-759.

Sharan M, Vovenko EP, Vadapalli A, Popel AS, Pittman RN (2008) Experimental and theoretical studies of oxygen gradients in rat pial microvessels. J Cereb Blood Flow Metab 28:1597-1604.

Srinivasan VJ, Sakadžić S, Gorczynska I, Ruvinskaya S, Wu W, Fujimoto JG, Boas DA (2010) Quantitative cerebral blood flow with Optical Coherence Tomography. Opt Express 18:2477-2494.

Theer P, Denk W (2006) On the fundamental imaging-depth limit in twophoton microscopy. J Opt Soc Am A Opt Image Sci Vis 23:3139-3149.

Thompson JK, Peterson MR, Freeman RD (2003) Single-neuron activity and tissue oxygenation in the cerebral cortex. Science 299:1070-1072.

Tian P, Teng IC, May LD, Kurz R, Lu K, Scadeng M, Hillman EM, De Crespigny AJ, D’Arceuil HE, Mandeville JB, Marota JJ, Rosen BR, Liu TT, Boas DA, Buxton RB, Dale AM, Devor A (2010) Cortical depth-specific microvascular dilation underlies laminar differences in blood oxygenation level-dependent functional MRI signal. Proc Natl Acad Sci U S A 107:15246-15251.

Vanzetta I, Grinvald A (1999) Increased cortical oxidative metabolism due to sensory stimulation: implications for functional brain imaging. Science 286:1555-1558.

Vazquez AL, Fukuda M, Tasker ML, Masamoto K, Kim SG (2010) Changes in cerebral arterial, tissue and venous oxygenation with evoked neural stimulation: implications for hemoglobin-based functional neuroimaging. J Cereb Blood Flow Metab 30:428-439.

Viswanathan A, Freeman RD (2007) Neurometabolic coupling in cerebral cortex reflects synaptic more than spiking activity. Nat Neurosci 10:1308-1312.

Vovenko E (1999) Distribution of oxygen tension on the surface of arterioles, capillaries and venules of brain cortex and in tissue in normoxia: an experimental study on rats. Pflugers Arch 437:617-623.

Yaseen MA, Srinivasan VJ, Sakadžić S, Wu W, Ruvinskaya S, Vinogradov SA, Boas DA (2009) Optical monitoring of oxygen tension in cortical microvessels with confocal microscopy. Opt Express 17:22341-22350. 